The full ruling can be found at:

http://www.asa.org.uk/Rulings/Adjudications/2013/6/Supercar-

Lifestyle-Ltd/SHP_ADJ_225392.aspx

Jisue Glinnis Lee, work experience student, Osborne Clarke

\title{
OFT publishes guidance on ongoing contracts with consumers
}

\author{
Aisling Pringleton \\ Journal of Direct, Data and Digital Marketing Practice (2013) 15, 85-87. \\ doi:10.1057/dddmp.2013.42
}

Topic: Advertising regulation

Who: The Office of Fair Trading (OFT)

Where: United Kingdom

When: June 2013

Law stated as at: 5 August 2013

What happened

\section{Common problems associated with ongoing contracts}

The OFT has published new guidance, entitled 'Key Issues in Ongoing Contracts', in relation to ongoing or longer-term contracts with consumers. The guide builds on a report carried out by the OFT in 2010 on consumer contracts, which highlighted those terms that can be particularly harmful to consumers. The report notes significantly (although perhaps not unexpectedly) that consumers rarely read contracts in full before entering into them, with the result that they are often unaware of the terms to which they have agreed.

Although it is very difficult to police this, the study found that even where consumers are taking reasonable care in reading the contracts, they are still making mistakes in interpreting important contractual terms. On the basis of the 2010 study and the recent experience of enforcers working in this area, the OFT has published the guidance in order to help to address common problems faced by consumers that arise from ongoing contractual relations with service providers.

Ongoing contracts involve often long-term contracts between consumers and suppliers that involve repeat or regular supply of goods and services, for example, club or membership subscriptions, insurance contracts, telecoms and broadcast service packages, banking services, and utilities. The OFT observes that consumers can experience a range of problems in their ongoing contractual relations with businesses, particularly as contracts involving longer-term relations can be more complex and often based on a business' standard terms, which are rarely reviewed or tailored to meet individual customer needs.

Perhaps because of the longer periods of time over which the contracts are performed, customers appear to be more tolerant of problems. This, coupled with lethargic efforts towards switching, means that consumers become locked into unfavourable agreements. 


\section{Consumers exploited later in contracts}

\section{Excessive minimum durations}

The OFT guide focuses on four key areas in which problems are frequently encountered and which distort competition within the market:

\section{(a) Information}

The OFT argues that consumers should be provided with sufficient information before, during and after entering into a contract, in order to enable them to make informed choices. Where any information is incorrect or misleading, too vague, or — perhaps most significantly — not prominent enough, businesses may try to exploit consumers or surprise them with hidden charges or unexpected limitations some time into the contract. It is therefore often easier for the consumer to continue with a contract, rather than successfully extricate themselves and find a replacement on more favourable terms.

(b) Cancellation

The OFT found that problems may arise particularly in respect of contracts that create tie-ins or impose restrictions on cancelling or switching to an alternative provider, for example, by setting an excessive minimum duration period, imposing high-exit fees or setting unduly burdensome exit fees for termination. In these circumstances, consumers will effectively be prevented from switching away from a supplier that provides a poor level of service (even where a better supplier could easily be found), as breaking the contract may be too harmful to that consumer.

The OFT has provided examples of harmful cancellation provisions, noting in particular provisions where:

- consumers are not made sufficiently aware of small print terms and conditions;

- tie-ins or other conditions are not sufficiently clear for them to be fully understood by consumers;

- tie-ins are unreasonably onerous, or cancellation charges are unreasonably high; and

- insufficient information is provided to consumers to enable them to accurately assess whether or not they are likely to want to switch.

\section{(c) Rollover/renewal}

The OFT noted that contracts where a consumer is made to sign up to a minimum contract period (which is automatically renewed unless the consumer informs the contract provider that he does not want this to happen) can be highly detrimental to consumers. Difficulties arise particularly where:

- only a limited window is allowed where the consumer may switch without incurring additional cost;

- the rollover is not disclosed to consumers at the time of entry into the contract;

- the supplier uses small print to disclose onerous cancellation charges;

- the supplier uses intentionally awkward procedures for cancellation or opt-out or 
- the supplier fails to highlight that the subsequent tie-in period involves a less favourable price or other terms than the first.

'Rollover' most often happens in the context of a free trial of a certain product or service, where consumers are offered a free trial of a product and are then moved on to a full-price service at the end of the trial. This can be harmful if, for example, consumers are not made aware that they will be 'rolled' into a contract that they will subsequently be obliged to pay for, are not provided with enough information about the contract, or cannot easily cancel the contract.

Importantly, however, the OFT notes that, in some circumstances, there can be benefits to gain from 'rollover' contracts, such as car insurance contracts that ensure that legal obligations to maintain car insurance are not accidentally breached by consumers. Such contracts will have to be carefully considered, however, to ensure that sufficient protections are given to consumers and that the benefits are not reflected solely onto the service provider.

\section{Danger in lack of right to cancel}

\section{Why this matters}

(d) Variation

Ongoing contracts that include terms permitting variation, especially of price, can be dangerous where the consumer does not have the right to cancel and, significantly, have a wider impact on the market because businesses are not constrained by having to stick to the (often very favourable) initial terms offered to lure a customer away from the business' competitors.

Variation during a contract is likely to be harmful where the initial terms change (after only a limited period) to significantly more expensive or less favourable ones. Other circumstances where variation would be unjustified are where the variation is disproportionate or linked to factors outside the supplier's control, where variation is unexpected as information notifying the consumer that this would be likely has not been made sufficiently clear, or, significantly, where the customer is tied into the contract and cannot cancel even with the sudden variation.

Although the OFT's guide is aimed primarily at enforcement officers, it provides a useful and detailed summary of the legal framework in this area, setting out the most relevant pieces of legislation and summarizing the most notable cases. Looking forwards, the OFT, and subsequently the Competition and Markets Authority, will retain the lead role for the enforcement of unfair contract terms legislation, and will provide business guidance in this area, together with a range of consumer enforcement powers.

The government has also published a draft Consumer Rights Bill, which is scheduled to be put before Parliament in 2013/14 and will implement the EU's Consumer Rights Directive. This puts forward proposals on redress, remedies and investigation powers for enforcement and considers revising the terms on unfair terms in consumer contracts currently set out in the Unfair Terms in Consumer Contracts Regulations 1999 and the Unfair Contract Terms Act 1977. There is therefore plenty to look out for over the coming months in this space.

Aisling Pringleton, Trainee Solicitor, Osborne Clarke 